\title{
REFINER PRODUCTION OF SODIUM PERBORATE AND HYDROGEN PEROXIDE BLEACHED MECHANICAL PULP: CHARACTERIZATION AND PHYSICOMECHANICAL PROPERTIES
}

\author{
ATÍLA GÜRHAN ÇELIK* and GAYE ÖZGÜR ÇAKAL** \\ *Department of Civil Engineering, Engineering Faculty, Giresun University, 28200, Giresun, Turkey \\ ${ }^{* * *}$ Institute of Nuclear Sciences, Ankara University, 06100, Ankara, Turkey \\ ¿ Corresponding author: G. Çakal, gcakal@ankara.edu.tr
}

Received January 15, 2020

Paper can be manufactured without bleaching, but high quality white paper grades, which require bleaching, are in demand as well. In paper mills, oxidizing or reducing chemicals are utilized to bleach the pulp. In this study, the utilization of sodium perborate, instead of the generally used sodium dithionite, to brighten mechanically produced wood pulp was investigated. Sodium perborate was chosen, as it is an environmentally friendly chemical and is produced in Turkey - from tincal, one of the boron ores in Turkey. The experiments were performed at Milda Aksu Paper Mill, using fresh pulp. The amount of bleaching chemicals was adjusted so that the dry mechanical pulp contained $0.5-2 \%$ more active oxygen. These chemicals were used either alone or in combination to see their bleaching effects. It was seen that the use of $2 \%$ sodium perborate together with $1.5 \%$ hydrogen peroxide gave better ISO brightness values $(68 \%)$ than that of the dithionite bleached (64\%) pulps. Under these conditions, fringing and fiber to fiber bonding was more pronounced than in the case of the paper from dithionite bleached pulp, which shows the advantage of using perborate in the bleaching process. Besides, the physico-mechanical properties of the produced paper sheets increased noticeably.

Keywords: mechanical pulp, sodium perborate, hydrogen peroxide, paper mill, brightness, physico-mechanical properties

\section{INTRODUCTION}

The rapidly increasing world population enhances the need for and, consequently, the consumption of paper and paperboard. Although some paper grades can be pressed without bleaching, like newspaper, high quality white paper grades require bleaching. As known, wood is one of the major raw materials used in the pulp and paper industry. The global pulp production capacity totalled 152.8 Mtpy at the end of 2013. The most widely used process is chemical pulping, which accounts for nearly three quarters of the total capacity (119.4Mtpy). The capacity for mechanical pulp totalled $12.1 \mathrm{Mtpy}, 8 \%$ of the global total. ${ }^{1}$

Wood is composed of cellulose fibers, carbohydrates, such as hemicelluloses, as well as lignin, which acts as an adhesive substance for the cellulose fibers. The pulp and paper industry breaks down the wood to separate the cellulose from the non-cellulose substances. ${ }^{2}$
In order to get rid of the pale-yellow color similar to that of natural wood, which is caused by the presence of lignin chromophores, pulp needs to be bleached. In a mill, the brightness of a pulp is widely used as an indication of its whiteness and it is an important criterion of its appropriateness for making white paper. The brightness of pulp is also used to evaluate the bleaching process. ${ }^{3}$ A brightness of about 55-65 is common for unbleached mechanical pulps, which may be raised to the range of $65-75$ by bleaching. ${ }^{4}$

Bleaching can be done with several chemicals, such as sodium dithionite (sodium hydrosulphite), ${ }^{5,6}$ sodium bisulfite, ${ }^{7}$ sodium perborate, ${ }^{8,9}$ sodium percarbonate, ${ }^{10,11}$ sodium borohydride, $^{12}$ amine borane, $^{13}$ hydrogen peroxide, ${ }^{14-16}$ magnesium hydroxide, ${ }^{17,18}$ acetic acid, ${ }^{19} \quad \mathrm{H}_{2} \mathrm{O}$ soluble ruthenium - phosphine complex $^{20}$ or enzymes, such as xylanase. ${ }^{21,22}$ For bleaching purposes, dithionite, peroxides and Cellulose Chem. Technol., 54 (7-8), 735-743(2020) 
hydro sulfites are utilized in mills. Oxygen, hydrogen, peroxide, ozone, peracetic acid, sodium hypochlorite, chlorine dioxide, chlorine and other chemicals are also used to convert the lignin to an alkaline soluble form. Unlike hydrogen peroxide, sodium percarbonate and sodium perborate are alkaline reactants and do not need extra caustic soda $(\mathrm{NaOH})$ for the bleaching activity. ${ }^{9}$ It has been reported that a short alkaline pretreatment can improve the performance of the peroxide bleaching stage, whereas harsh alkaline conditions result in the formation of peroxideresistant chromophores, ${ }^{23}$ accelerate selfdecomposition, prevent brightening and reduce its effect. $^{24}$

While decolorizing the wood's lignin, the most often utilized beaching agent sodium dithionite does not dissolve organic material from the pulp. ${ }^{1}$ However, residual dithionite in the pulp can cause corrosion of metallic components downstream in the process. In most mills, a metal chelating agent, such as EDTA, is used to prevent degradation of the dithionite. ${ }^{25}$ EDTA is also used as a stabilizer, which is used for the control of perhydroxyl ion to prevent rapid decomposition of bleach and to minimize fiber degradation. ${ }^{26}$ Hydrogen peroxide, on the other hand, mainly due to alkalinity during bleaching, results in some dissolution of organic substances in the wood. The bleaching process results in lower brightness in the presence of heavy metal ions; therefore, chelating agents are usually added before bleaching to form complexes with heavy metals, which prevents the pulp from discoloring and the peroxide from decomposing. Furthermore, peroxide bleaching improves the strength and water uptake capacity of the pulp.

Sodium perborates, $\mathrm{NaBO}_{3} \cdot \mathrm{nH}_{2} \mathrm{O}$, are environmentally friendly oxygen-based chemicals, which are used as peroxide-releasing compounds either alone or in combination with other chemicals. Sodium perborate monohydrate and tetrahydrate liberates $15 \%$ and $10.2 \%$ active oxygen, respectively, during bleaching. Hydrogen peroxide, on the other hand, is a strong oxidizer and has a fast oxidizing rate in basic medium. It liberates $47 \%$ active oxygen, which could increase the active oxygen amount of the pulp.

This is a comparative study to investigate the effect of sodium perborate with/without hydrogen peroxide during pulp bleaching. These chemicals have been tested as a substitute for the conventional bleaching chemical, sodium dithionite. Unlike in other studies, the experiments were performed at the mill's laboratory, using fresh pulp of Fagus orientalis and different bleaching chemicals. The characterization and physico-mechanical tests were also performed in order to observe the effects of bleaching chemicals on the produced paper sheets.

\section{EXPERIMENTAL \\ Materials}

Fresh pulp (Fagus orientalis) from Milda Aksu Mill, hydrogen peroxide $\left(\mathrm{H}_{2} \mathrm{O}_{2}\right)$, sodium perborate monohydrate $\left(\mathrm{NaBO}_{3} \cdot \mathrm{H}_{2} \mathrm{O}\right.$, PBS- 1$)$ and sodium perborate tetrahydrate $\left(\mathrm{NaBO}_{3} \cdot 4 \mathrm{H}_{2} \mathrm{O}, \mathrm{PBS}-4\right)$ were used during the bleaching experiments. Sodium perborate monohydrate and sodium perborate tetrahydrate were provided by Eti Mine Works, Ankara, Turkey, while hydrogen peroxide, ethylenediaminetetraacetic acid, widely abbreviated as EDTA, and $\mathrm{NaOH}$ were purchased from Merck.

A cylindrical stainless steel tank, with a diameter of $30 \mathrm{~cm}$ and height of $60 \mathrm{~cm}$, with a mechanical stirrer, was used for the bleaching process.

\section{Experimental procedure}

Before the bleaching process, 20 grams of fresh pulp on dry basis was pretreated with $0.4 \%$ EDTA at $65-70{ }^{\circ} \mathrm{C}$ for 15 minutes to remove undesirable heavy metal ions. The pulp consistency was $3.5-4 \%$ at this stage. The $\mathrm{pH}$ of the medium was adjusted to 9.5 with $\mathrm{NaOH}$. The obtained mechanical pulp was put into deionized water and then treated with the bleaching chemicals for 15 minutes. The hydrogen peroxide, perborate monohydrate, sodium perborate tetrahydrate and sodium dithionite used had active oxygen content in the range of $0.5-3 \mathrm{wt} \%$.

During the bleaching stage, the temperature was 90 ${ }^{\circ} \mathrm{C}$ and $\mathrm{pH}$ was 5.0. The amount of bleaching chemicals was adjusted so that the dry mechanical pulp contained $0.5-2 \%$ more active oxygen. These chemicals were used either alone or in combination to see their bleaching effects. The bleached pulp taken from the tank was filtered after $60 \mathrm{~min}$. Brightness tests, characterization tests and physico-mechanical tests were performed in order to see the effect of bleaching on the paper sheets.

\section{Brightness tests}

Thin sheets were prepared by using a Frank-PTI Rapid Köthen Sheet Machine and the brightness of the sheets was measured by a Minolta CM-2600d spectrophotometer according to ISO 2470-1977 (E) standards. The brightness of a sheet was measured on two sides - front and back. The averages were calculated and used for comparison during the study.

\section{Characterization tests}

The characterization of unbleached and bleached 
papers was performed by X-ray diffraction (XRD), scanning electron microscopy (SEM) analysis and energy dispersive X-ray spectroscopy (EDS) analysis. The XRD of the samples was carried out by using a Rigaku D/MAX 2200 PC model XRD, equipped with a $\mathrm{Cu} \mathrm{X}$-ray tube. XRD patterns were recorded in the range of $2^{\circ}<2 \theta<80^{\circ}$, with a step of $0.02^{\circ}$. SEM images and the elemental composition of the samples were obtained by a LEO 1430 VP model SEM instrument, equipped with EDS detector. Proportional elemental distribution was found by the EDS analyzer.

\section{Physico-mechanical tests}

The mechanical strength of the sheets was measured with a Zwick/Roell Z2.5 according to ISO 3781. Tensile index was found by using a Tensile Compression Testing Machine DVT GP E GN. The tear index was determined according to TS EN ISO 12625-4, using an Elmendorf Tearing Strength Tester ZGT 7055, which is used for determining the tearing resistance of paperboards. The density of the papers was determined according to ISO 287, and water absorption and water holding capacity (COBB) tests were done according to ISO 12625. Five samples were prepared for each test.

\section{RESULTS AND DISCUSSION}

Bleaching experiments were performed to determine the amounts of bleaching chemicals that would yield higher brightness values, compared to that achieved by sodium dithionite bleaching. The papers were then characterized using XRD and SEM-EDS analyses, and physicomechanical tests were also performed.

\section{Effect of bleaching on the brightness of paper sheets}

In this study, before treating the pulp with bleaching chemicals, it was treated with EDTA, as EDTA forms complexes with heavy metal ions and prevents the formation of colored structures. The experimental conditions were kept constant in order to see the effect of bleaching chemicals on the brightness. The ISO brightness of the unbleached pulp was found as $50.7 \%$, whereas sodium dithionite $(3 \%)$ bleached pulp gave an ISO brightness of $64.0 \%$. These values were compared with those of the sodium perborate and hydrogen peroxide bleached pulps throughout the study.

The effect of the amount of bleaching chemicals (1-3\%) - hydrogen peroxide (P), sodium perborate monohydrate (PBS-1) and tetrahydrate (PBS-4) - on the ISO brightness of the paper is examined in Figure 1. It may be observed that hydrogen peroxide bleaching gave higher ISO brightness values than that of the perborates. The highest ISO brightness was found as $63.6 \%$ when the pulp was bleached with a hydrogen peroxide charge of $3 \%$. That represents a $12.9 \%$ increase in ISO brightness, compared with that of the unbleached pulp. The use of hydrogen peroxide bleaching agents yielding up to $10 \%$ higher brightness has been also reported. ${ }^{1}$ When perborates were compared, it was noted that sodium perborate monohydrate (PBS-1) whitened the paper more than sodium perborate tetrahydrate (PBS-4), reaching 56.2\% ISO brightness when the pulp was treated with a sodium perborate monohydrate charge of $3 \%$. As PBS-1 has higher active oxygen content than PBS-4, this result is quite reasonable. The dashed line in the figures denotes the ISO brightness of the unbleached paper $-50.7 \%$. Although higher brightness values were found compared to the unbleached paper, it was aimed to reach at least the ISO brightness of sodium dithionite $64 \%$. In a study done by Varennes et al., ${ }^{8}$ it has been found that ISO brightness can be increased by $15 \%$ by sodium perborate bleaching.

To increase the bleaching effect, hydrogen peroxide was used together with PBS-1 and PBS4. First, to determine the most suitable order of addition of bleaching chemicals to the pulp, $1 \%$ PBS-1 and 0.5-3\% hydrogen peroxide were added sequentially according to the bleaching process described. The comparison is given in Figure 2. First of all, it should be mentioned that all ISO brightness values were above that of the unbleached paper. However, when PBS-1 and hydrogen peroxide up to $1 \%$ were used, higher ISO brightness values were obtained with the PBS-1 - hydrogen peroxide addition sequence. On the other hand, when PBS-1 and 1.5-2.5\% hydrogen peroxide were used in the reverse addition sequence, much higher ISO brightness values were obtained. When $3 \%$ hydrogen peroxide was used, there seemed to be no difference in the ISO brightness values with varying the addition sequence. Except the 0.5\% hydrogen peroxide experiments, comparable or higher ISO brightness values were reached with perborate addition after hydrogen peroxide. Thus, the rest of the experiments were performed with this order. 


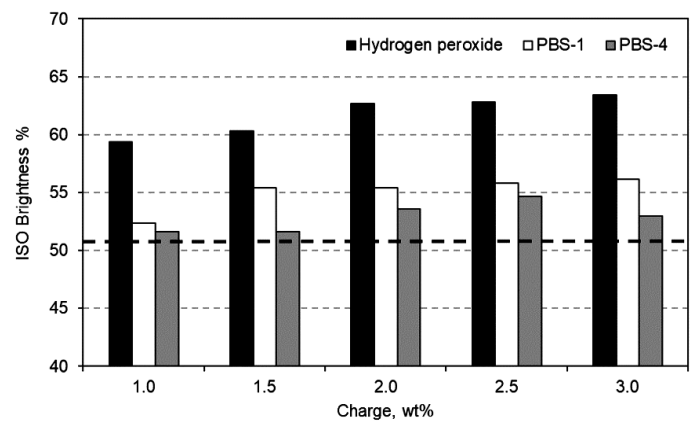

Figure 1: ISO brightness of papers bleached with different percentages of hydrogen peroxide, sodium perborate monohydrate, PBS-1 and sodium perborate tetrahydrate, PBS-4 (the dashed line denotes the brightness value of the unbleached paper)

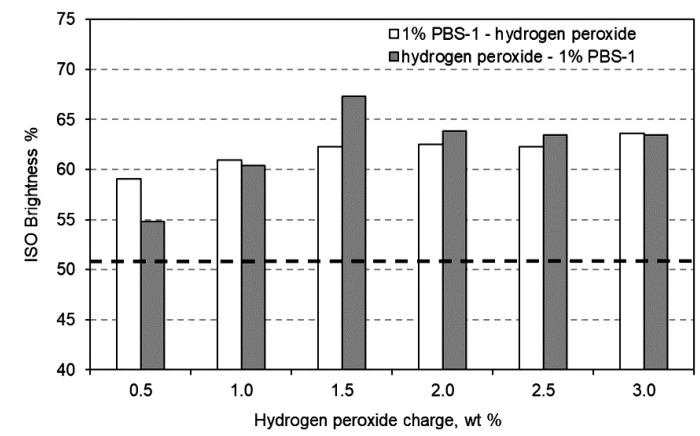

Figure 2: ISO brightness of papers bleached with hydrogen peroxide and $1 \%$ sodium perborate monohydrate, PBS-1 in different addition orders (the dashed line denotes the brightness value of the unbleached paper)

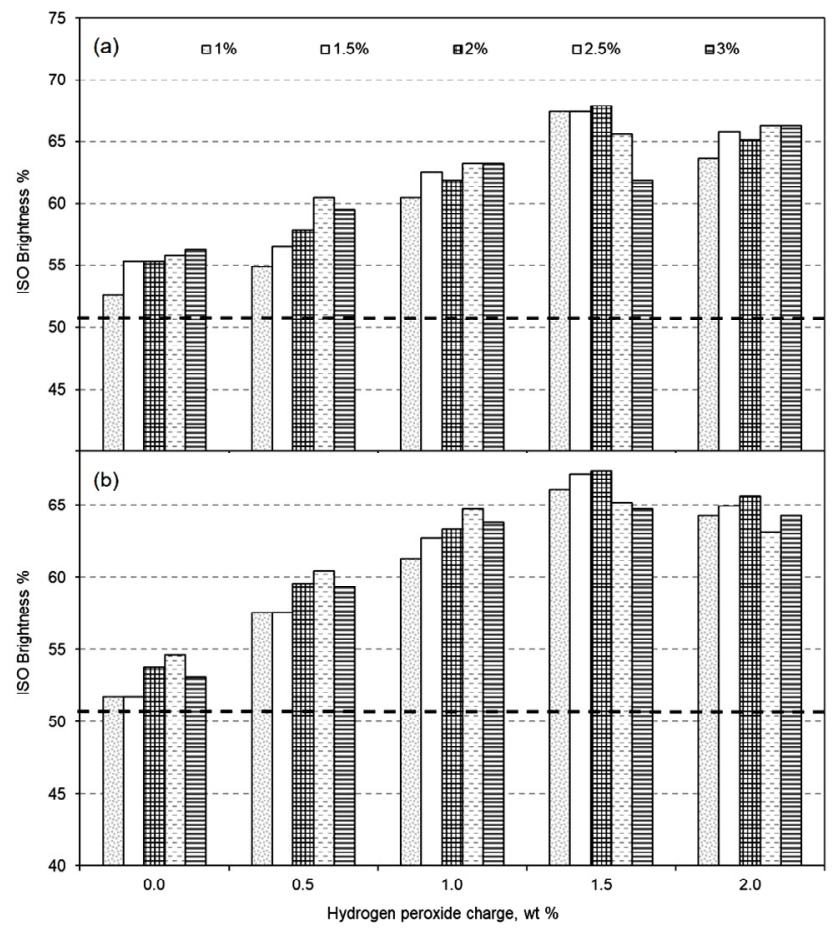

Figure 3: ISO brightness of papers bleached with different hydrogen peroxide and (a) sodium perborate monohydrate, PBS-1 or (b) sodium perborate tetrahydrate, PBS-4 percentages (the dashed line denotes the brightness value of the unbleached paper)

For bleaching processes with hydrogen peroxide and PBS-1 or PBS-4, an additional treatment time of 15 min for hydrogen peroxide was added to this two-step bleaching process. The ISO brightness values of the bleached papers at different active oxygen percentages of hydrogen peroxide $(0.5-3 \%)$ and PBS-1 (1-3\%) or PBS-4
$(1-3 \%)$ are presented in Figure $3 \mathrm{a}$ and $3 \mathrm{~b}$, respectively. As observed, the highest ISO brightness value of $68.1 \%$ was obtained when $1.5 \%$ hydrogen peroxide and 2\% PBS-1 (Fig. 3a) were used, whereas an ISO brightness value of $67.5 \%$ was obtained when $1.5 \%$ hydrogen peroxide and 2\% PBS-4 (Fig. 3b) was used. As 
seen, the optimum active oxygen percentage of perborate should be $2 \%$ to obtain a higher ISO brightness. There is an increase of $17.4 \%$ in the brightness of the paper, with respect to the unbleached one, when $1.5 \%$ hydrogen peroxide and $2 \%$ PBS-1 were used, which is also $4.1 \%$ higher than the value for the dithionite bleached pulp $(64.0 \%)$. This increase in the brightness of the pulp is quite convincing.

The brightening effect when using three bleaching chemicals together was investigated in Figure 4 . The hydrogen peroxide charge of $0.5 \%$ was used, with different concentrations of PBS-1 $(0.5-3 \%)$ and PBS-4 (0.5-3\%). The highest brightness value, $61.8 \%$, was found when $2 \%$ PBS-1 and 2\% PBS-4 were used, which corresponds to an $11.1 \%$ increase in the brightness of the pulp. The use of the three chemicals together did not have a better effect than the use of two chemical combinations (Fig. 3 $a, b)$.

\section{Characterization of bleached papers}

In order to characterize the bleached papers, the microstructure of unbleached, dithionite $(1.5 \%)$ bleached and hydrogen peroxide $(0.5 \%)-$ PBS-1 (1.5\%) bleached papers were analyzed by using XRD (Fig. 5). A comparison of the XRD patterns in Figure 5 revealed that all the papers essentially had the same microstructure. The bleaching chemicals did not change the structure of the paper, but decreased the intensity. The peaks of all the patterns matched the XRD peaks of cellulose, $\left(\mathrm{C}_{6} \mathrm{H}_{10} \mathrm{O}_{5}\right)_{\mathrm{n}}$ (PDF Card No. 00-0502241).
As known, cellulose molecules are bound to build up hydrogen bonds within the molecule and between different molecules. The hydrogen bonds also play an important role in the mechanical properties of the cellulosic materials. Besides its complex crystalline structure, native cellulose also has a complex arrangement within the wood fiber wall. ${ }^{27}$ In this study, SEM analyses were performed to characterize the morphology and to investigate the microstructure of the cellulose fibers. The purpose of adding bleaching chemicals to the pulp was to whiten the papers without damaging the fiber structure, thus the mechanical strength. Representative SEM images (magnification of 1000x) of unbleached and bleached papers are presented in Figure 6. The SEM image of the unbleached paper (Fig. 6 a) shows that the cellulose fibers are apart from each other and the dimensions of the fibers differ. The physical properties of the resulting paper will be low because of very slight fringing in the fibers. In Figure 6 b, it may be observed that sodium dithionite $(1.5 \%)$ bleached paper has thicker fibers, however fiber to fiber bonding was more pronounced, compared to that in the unbleached paper. In the case of hydrogen peroxide (1.5\%)PBS-1 (2\%) bleached paper (Fig. 6 c), fringing and fiber to fiber bonding were stronger than in the dithionite bleached paper, which shows the advantage of using perborate in the bleaching process. Perborates can improve the strength of the paper by contributing to the formation of bonds among the fibers, while whitening the papers.

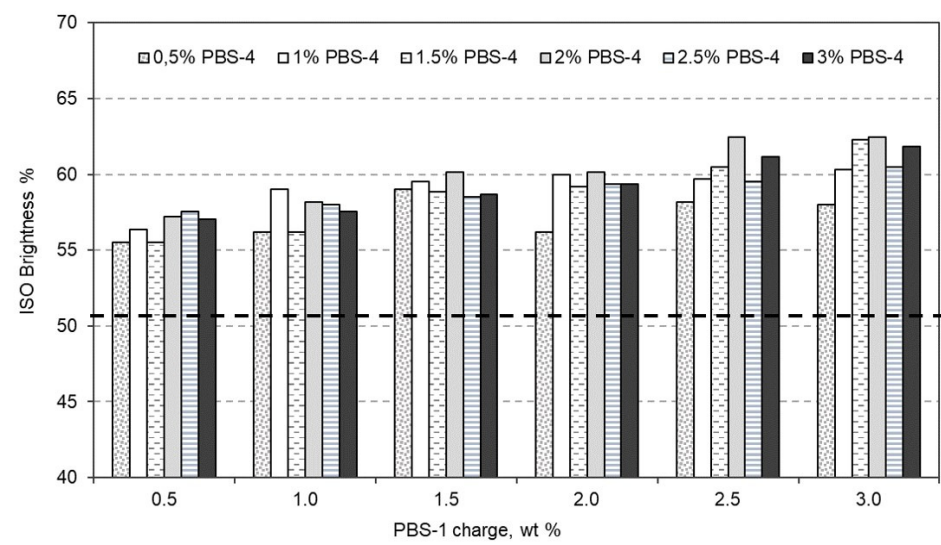

Figure 4: ISO brightness of papers bleached with different sodium perborate monohydrate, PBS-1, and sodium perborate tetrahydrate, PBS-4, percentages (the hydrogen peroxide charge of $0.5 \%$ was kept constant; the dashed line denotes the brightness value of the unbleached paper) 
After the papers were manufactured from the pulps, the bulk composition of the papers was examined by determining their elemental composition by EDS (Table 1). The bleached papers, regardless of the bleaching chemical, had similar carbon and oxygen percentages, as seen from Table 1. The elemental composition and $\mathrm{C} / \mathrm{O}$ ratios of the bleached papers were slightly different from those of the unbleached paper. It should be noticed that the elemental composition of the papers was not altered by the bleaching process.

\section{Physico-mechanical tests of bleached papers}

The physico-mechanical changes occurring in the sheets due to the bleaching process were examined (Table 2).

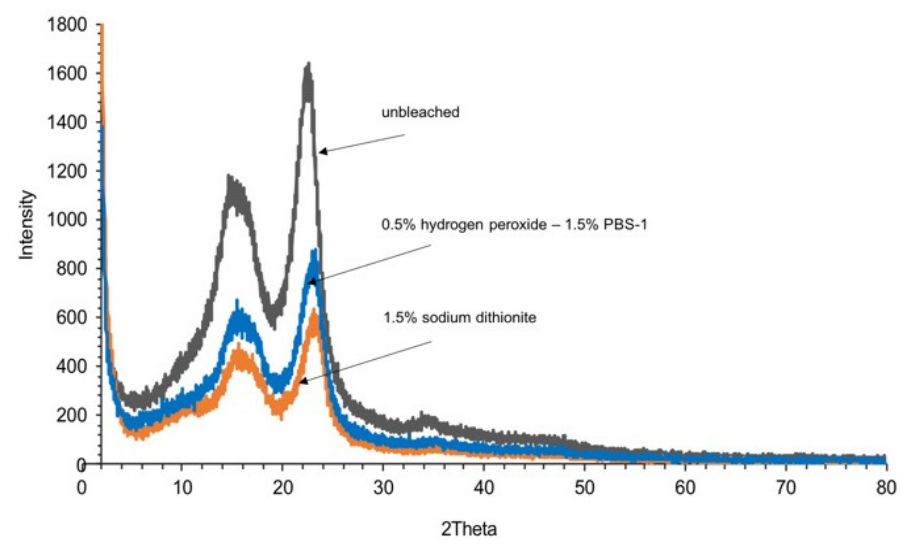

Figure 5: Comparison of XRD patterns of unbleached and bleached papers
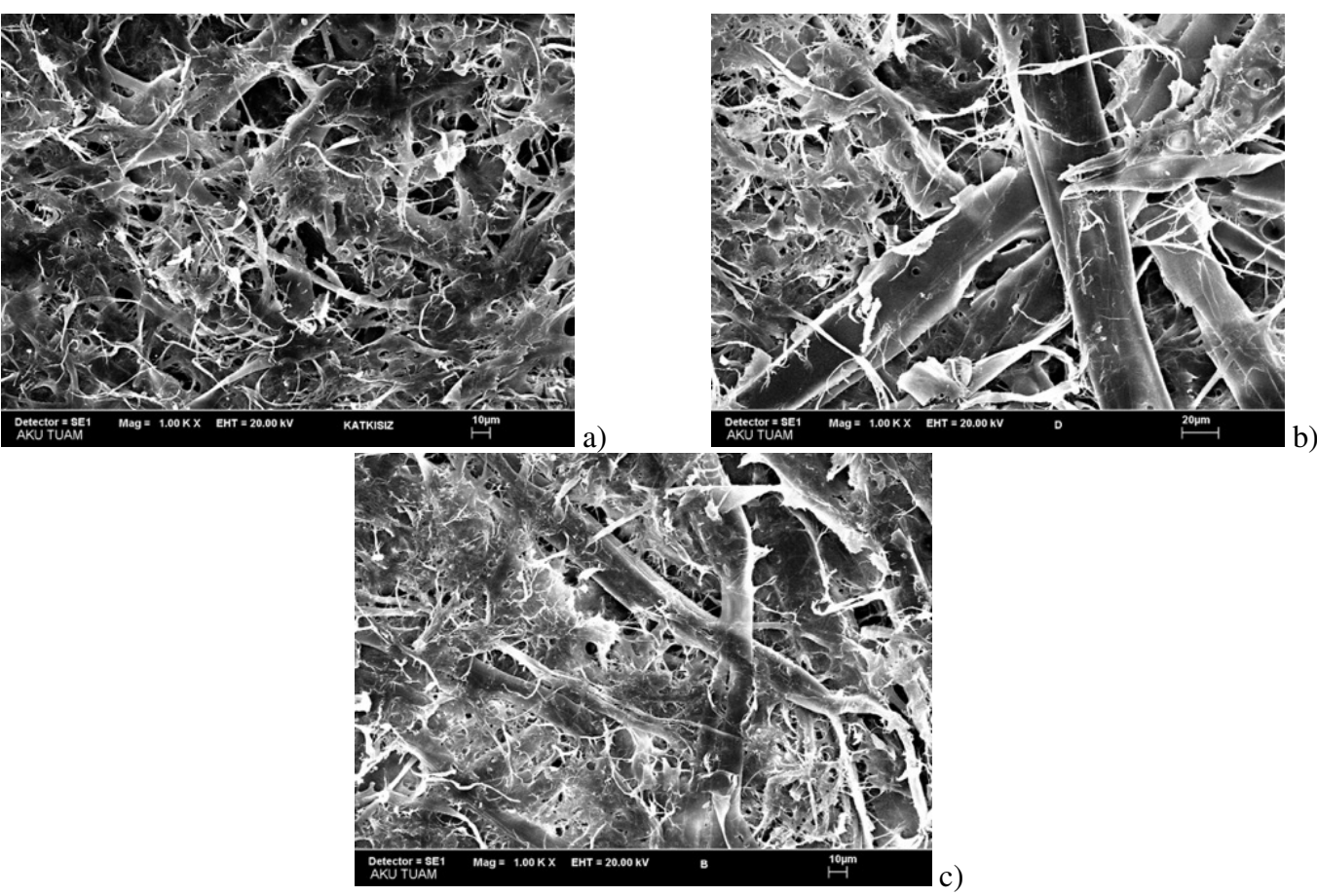

Figure 6: SEM images of (a) unbleached, (b) dithionite (1.5\%) bleached and (c) hydrogen peroxide (1.5\%)PBS-1 (2\%) bleached papers 
Table 1

Elemental composition (wt\%) of papers obtained by EDS

\begin{tabular}{lccc}
\hline Paper type & Carbon, \% & Oxygen, \% & C/O ratio \\
\hline Unbleached & 34.4 & 65.6 & 0.52 \\
Sodium dithionite (1.5\%) bleached & 37.1 & 62.9 & 0.59 \\
Hydrogen peroxide (1.5\%)_PBS-1 (2\%) bleached & 37.5 & 62.5 & 0.60 \\
\hline
\end{tabular}

Table 2

Physico-mechanical test results and ISO brightness values for paper sheets prepared from unbleached and bleached pulps

\begin{tabular}{|c|c|c|c|c|c|c|c|c|}
\hline Bleaching agent & $\underset{\%}{\text { Amount, }}$ & $\begin{array}{l}\text { Density, } \\
\mathrm{g} / \mathrm{m}^{3}\end{array}$ & $\begin{array}{l}\text { Tear index, } \\
\mathrm{mNm}^{2} / \mathrm{g}\end{array}$ & $\begin{array}{c}\text { Tensile index, } \\
\mathrm{Nm} / \mathrm{g}\end{array}$ & $\begin{array}{c}\text { Water } \\
\text { absorption } \\
\text { time, } s\end{array}$ & $\begin{array}{c}\mathrm{COBB}, \\
\mathrm{g} / \mathrm{m}^{2}\end{array}$ & $\begin{array}{l}\text { Mechanical } \\
\text { strength, } \\
\mathrm{N} / \mathrm{m}\end{array}$ & $\begin{array}{c}\text { ISO } \\
\text { brightness, } \\
\%\end{array}$ \\
\hline Unbleached & - & $0.30 \pm 0.04$ & $6.21 \pm 0.14$ & $20.01 \pm 0.25$ & $1.81 \pm 0.15$ & $16 \pm 4$ & $385.4 \pm 0.1$ & $50.7 \pm 0.2$ \\
\hline Dithionite & 3 & $0.32 \pm 0.01$ & $7.23 \pm 0.09$ & $25.20 \pm 0.19$ & $1.26 \pm 0.17$ & $20 \pm 3$ & $387.6 \pm 0.5$ & $64.0 \pm 0.3$ \\
\hline Hydrogen peroxide $(\mathrm{P})$ & 3 & $0.33 \pm 0.05$ & $7.34 \pm 0.11$ & $30.06 \pm 0.22$ & $1.21 \pm 0.09$ & $21 \pm 4$ & $390.7 \pm 0.4$ & $63.6 \pm 0.1$ \\
\hline PBS-1 & 3 & $0.35 \pm 0.07$ & $7.36 \pm 0.15$ & $35.62 \pm 0.27$ & $1.13 \pm 0.12$ & $21 \pm 3$ & $395.4 \pm 0.2$ & $56.4 \pm 0.3$ \\
\hline PBS-4 & 3 & $0.35 \pm 0.01$ & $7.43 \pm 0.10$ & $37.77 \pm 0.33$ & $1.08 \pm 0.18$ & $22 \pm 2$ & $399.2 \pm 0.9$ & $53.3 \pm 0.2$ \\
\hline P/PBS-1/PBS-4 & $1.5 / 2 / 2$ & $0.36 \pm 0.03$ & $8.29 \pm 0.11$ & $40.15 \pm 0.36$ & $1.05 \pm 0.13$ & $24 \pm 3$ & $381.4 \pm 0.1$ & $61.8 \pm 0.2$ \\
\hline P/PBS-1 & $1.5 / 2$ & $0.37 \pm 0.02$ & $7.05 \pm 0.17$ & $37.61 \pm 0.31$ & $1.02 \pm 0.07$ & $18 \pm 2$ & $389.4 \pm 0.8$ & $68.1 \pm 0.3$ \\
\hline
\end{tabular}


As seen from Table 2, the bleaching process noticeably increased the density, tear index, tensile index, water holding capacity (COBB) and slightly increased the mechanical strength of the sheets, compared to the unbleached sheets. The obtained results also support the outcomes of SEM analysis. As the fiber thickness or fiber to fiber bonding increases as a function of the bleaching chemical used, these findings are quite predictable.

When the mechanical strength of sodium dithionite, hydrogen peroxide or perborate bleached sheets was compared with that of the unbleached sheet (Table 2), it was found that bleaching had no adverse effect on the mechanical strength of the papers.It was apparent that peroxide and peroxide/perborate bleaching improved the strength of the pulp more than sodium dithionite. This result also showed that sodium perborate did not damage the cellulosic matrix. This finding is similar to the result obtained for the sodium borohydride bleaching agent, as it produces paper with high finished strength and good brightness. ${ }^{1}$ It can be concluded that the use of boron as borohydride or perborate for bleaching improves the mechanical properties and brightness of the produced papers significantly. When Table 2 was examined in terms of both physico-mechanical properties and brightness values, it was seen that the use of hydrogen peroxide $(1.5 \%)$ and sodium perborate monohydrate $(2 \%)$ together gave the highest brightness value and increased the properties of the paper.

\section{CONCLUSION}

Sodium perborates, which are environmentally friendly chemicals, are easy to handle and cheaper than other bleaching chemicals, especially sodium dithionite and hydrogen peroxide. In order to have ISO brightness values comparable or higher than that of the sodium dithionite bleached pulp, the use of sodium perborate with hydrogen peroxide was investigated. As seen, an increase of $17.4 \%$ in the brightness of the paper with respect to the unbleached paper can be obtained when $1.5 \%$ hydrogen peroxide and 2\% PBS-1 were used together, which was also $4.1 \%$ higher than the corresponding value for the dithionite bleached pulp. This increase in the brightness of the pulp is quite convincing and it shows the feasibility of using these chemicals in mills. Besides, the physico-mechanical properties of the paper also increased. It was apparent that peroxide and peroxide/perborate bleaching improved the strength of the pulp more than sodium dithionite. As seen from the SEM images, perborates can improve the strength of the paper by contributing to the formation of bonds among fibers, while whitening the paper. Thus, sodium perborate can be a superior bleaching agent when used together with hydrogen peroxide.

ACKNOWLEDGEMENTS: The writers acknowledge the National Boron Research Institute, BOREN, for partial support through the project number BOREN-B0081 and to Milda Aksu Paper Mill for the laboratory opportunities offered throughout the study. We are grateful to the Geological Engineering Department, Hacettepe University, for XRD analysis, to the Technology Application and Research Center, Afyon Kocatepe University, for SEM-EDS analysis and to Murat Saka from Lila Paper Mill for the physico-mechanical tests.

\section{REFERENCES}

1 Roskill Information Services Ltd., "Boron: Global Industry Markets and Outlook", $13^{\text {th }}$ ed., London, 2015, https://roskill.com/market-report/boron/

2 G. Thompson, J. Swain, M. Kay and C. F. Forster, Bioresour. Technol., 77, $275 \quad$ (2001), https://doi.org/10.1016/S0960-8524(00)00060-2

3 P. Bajpai, "Environmentally Friendly Production of Pulp and Paper", John Wiley \& Sons, Inc., New Jersey, 2010, https://doi.org/10.1002/9780470649657

4 M. B. Hocking, "Handbook of Chemical Technology and Pollution Control", Academic Press, San Diego, 2006, https://www.elsevier.com/books/handbook-ofchemical-technology-and-pollutioncontrol/hocking/978-0-12-088796-5

5 M. E. Ellis, in "Pulp Bleaching - Principles and Practice", edited by C. W. Dence, D. W. Reeve, Tappi Press, Atlanta, 1996, pp. 491-512, https://imisrise.tappi.org/TAPPI/Products/01/B/0102B 061.aspx

6 G. Martin, H. Grussenmeyer and G. Becker, in Procs. International Mechanical Pulping Conference, Minneapolis, Minnesota, USA, 2007, pp. 615-616, https://www.tappi.org/content/events/07impc/07impc5 6.pdf

7 K. Kuys and J. Abbot, Appita J., 49, 269 (1996), http://ecite.utas.edu.au/8610

8 S. Varennes, C. Daneault and M. Parenteau, Tappi J., 79, $245 \quad$ (1996), https://imisrise.tappi.org/TAPPI/Products/96/MAR/96 MAR245.aspx

9 C. Leduc, M. M. Sain, C. Daneault, R. Lanouette and J. L. Valade, Tappi J., 83, 77 (2000, https://imisrise.tappi.org/TAPPI/Products/PUL/PULP9 
7471.aspx

10 C. Leduc, M. Garceau, C. Daneault and S. Robert, J. Pulp Pap. Sci., 28, 171 (2002), https://pascalfrancis.inist.fr/vibad/index.php?action=getRecordDetai 1\&idt=13695561

11 E. Pesman, S. Imamoglu, E. E. Kalyoncu and H. Kirci, BioResources, 9, 523 (2014), https://ojs.cnr.ncsu.edu/index.php/BioRes/article/view/ BioRes_09_1_523_Pesman_Sodium_Percarbonate_De inking

12 W. C. Mayer and C. P. Donofrio, Pulp Pap.-Can., 157 (1958),

https://www.bcin.ca/bcin/detail.app;jsessionid=569994 7730B0C04D5887B9E66CECF9A1 $\mathrm{id}=458733 \& \mathrm{pId}=$ $3 \&$ lang $=$ en $\&$ asq $=\& c s q=\& \operatorname{csa}=\& p s=50$

13 C. Pedneault, C. Pellerin and S. Robert, Tappi J., 82, 110 (1999), https://imisrise.tappi.org/TAPPI/Products/99/FEB/99F EB110.aspx

14 D. Lachenal, C. Bourne and C. Choudens, US Patent No: 4,756,798, 1988, https://patents.google.com/patent/US4756798A/en

15 A. A. Shatalov and H. Pereira, Bioresour. Technol., 96, 865

(2005), https://doi.org/10.1016/j.biortech.2004.09.005

16 J. R. Presley and R. T. Hill, in "Pulp Bleaching Principles and Practice", edited by C. W. Dence, D. W. Reeve, Tappi Press, Atlanta, 1996, pp. 457-458, https://imisrise.tappi.org/TAPPI/Products/01/B/0102B 061.aspx

17 R. Harrison, T. Parrish, A. Gibson, C. Knapp, M. Wajer et al., Tappi J., 91, 16 (2008), https://imisrise.tappi.org/TAPPI/Products/08/SEP/08S EP16.aspx

18 D. A. Johnson, S. Park, J. M. Genco, A. Gibson, M Wajer et al., In Procs. Tappi Pulping Conference, San Diego,

Atlanta,
https://imisrise.tappi.org/TAPPI/Products/FTC/FTC02 93.aspx

19 J. J. Villaverde, P. Ligero and A. Vega, Bioresour. Technol., $\quad \mathbf{1 0 0}, \quad 4731 \quad$ (2009), https://www.tappi.org/content/events/07impc/07impc0 5.pdf

20 T. Q. Hu and B. R. James, Canadian Chem. News, 56 , 27 (2004) https://issuu.com/canadianchemicalnews/docs/canadia nchemicalnews_apr2004

21 P. Sharma, C. Sood, G. Singh and N. Capalash, J. Clean. Prod., 87, $966 \quad$ (2015), https://doi.org/10.1016/j.jclepro.2014.09.083

22 M. B. Roncero, A. L. Torres, J. F. Colom and T. Vidal, Bioresour. Technol., 96, 21 (2005), https://doi.org/10.1016/j.biortech.2004.03.003

${ }_{23} \mathrm{Z}$. He, Y. Ni and E. Zhang, J. Wood Chem. Technol., 24, 1 (2004), https://doi.org/10.1081/WCT120035940

${ }^{24}$ H. Ren and S. Omori, Cellulose Chem. Technol., 46, 115

(2012), https://cellulosechemtechnol.ro/pdf/CCT12(2012)/p.115-120.pdf

25 P. Bajpai, "Green Chemistry and Sustainability in Pulp and Paper Industry", Springer, Switzerland, 2015, https://doi.org/10.1007/978-3-319-18744-0

26 S. R. Karmakar, "Chemical Technology in the Pretreatment Processes of Textiles", Elsevier Science, India, pp. 160-161, 1999, https://www.elsevier.com/books/chemical-technologyin-the-pre-treatment-processes-oftextiles/karmakar/978-0-444-50060-1

27 C.-M. Popescu, C. M. Tibirna, I. E. Raschip, M.-C. Popescu, P. Ander et al., Cellulose Chem. Technol., 42, $525 \quad$ (2008), https://cellulosechemtechnol.ro/pdf/CCT45,56(2011)/p.329-338.pdf 